\title{
Influence of Substrate Temperature on the Structural and the Electrical Properties of $\mathrm{CdIn}_{2} \mathrm{Se}_{4}$ Fhin Films
}

\author{
M.A.M. Seyam*, G.F. Salem and S.N.A. Aziz \\ *Department of Physics, Faculty of Education, \\ Ain Shams University, Egypt \\ email: Seyam80@yahoo.com
}

\begin{abstract}
CdIn ${ }_{2} \mathrm{Se}_{4}$ thin films of different thicknesses were prepared on pre-cleaned glass substrates by the thermal evaporation technique under vacuum $10^{-5}$ Torr. The influence of substrate temperature on the structural and the electrical properties has been studied. The crystal structure and orientation of the prepared films were investigated by $x$-ray diffraction. The $x$-ray analysis confirmed that thin films of $\mathrm{CdIn}_{2} \mathrm{Se}_{4}$ thermally evaporated at room temperature are polycrystalline with cubic crystal structure. The films were preferred orientation along plane (202). The crystallite size (ranged between $17.8 \mathrm{~nm}$ and $24.7 \mathrm{~nm}$ ) increases with increasing substrate temperature. The room temperature resistivity for the films deposited at room temperature was in the order of $10^{7} \Omega \mathrm{cm}$, which decreased to $10^{2} \Omega \mathrm{cm}$ for substrate temperature at $523 \mathrm{~K}$. The activation energy varied from $0.32 \mathrm{eV}$ to $0.22 \mathrm{eV}$ with increasing substrate temperature from $298 \mathrm{~K}$ to $523 \mathrm{~K}$. The thermoelectric power measurements of $\mathrm{CdIn}_{2} \mathrm{Se}_{4}$ thin films revealed that all deposited films at different substrate temperature were n-type semiconductors. The density of charge carriers of films grown at 298 and $498 \mathrm{~K}$ were $7.01 \times 10^{18}$ and $1.45 \times 10^{19}$ $\mathrm{cm}^{-3}$ respectively.
\end{abstract}

\section{Introduction}

$\mathrm{CdIn}_{2} \mathrm{Se}_{4}$ is a promising material in optoelectronic applications and solar cells [1,2] due to its high absorption coefficient in the visible region. $C d \operatorname{In}_{2} \mathrm{Se}_{4}$ thin films were prepared by different techniques $[3,4]$. The characterizations of $\mathrm{CdIn}_{2} \mathrm{Se}_{4}$ films were extensively studied [5-10]. The structural properties were investigated by means of $x$-ray diffraction. It has been revealed that $C d \operatorname{In}_{2} \mathrm{Se}_{4}$ has $a$ cubic structure with lattice parameter, $a=5.815 \AA[11,12]$.

No work was reported about the effect of substrate temperature on the structural and the conduction mechanisms of $\mathrm{CdIn}_{2} \mathrm{Se}_{4}$ thin films. The aim of the 
present work is to study the effect of substrate temperature on the structural, transport properties and conduction mechanisms of $C d \operatorname{In}_{2} \mathrm{Se}_{4}$ thin films.

\section{Experimental Techniques}

Powder of $\mathrm{CdIn}_{2} \mathrm{Se}_{4}$ was used to deposit the thin films of different thickness $(160 \mathrm{~nm}-700 \mathrm{~nm})$ were deposited on a pre-cleaned glass substrates using a high vacuum-coating unit (Edwards type E $306 \mathrm{~A}$ ) under vacuum $10^{-5}$ Torr. The deposition rate of the films was about $7 \mathrm{nms}^{-1}$. The substrate temperatures were set at $298 \mathrm{~K}, 330 \mathrm{~K}, 380 \mathrm{~K}, 395 \mathrm{~K}, 460 \mathrm{~K}$ and $523 \mathrm{~K}$. Thin tantalum boat was used as source heater. The film thickness was measured by Tolansky's method [13]. The rate of deposition and the film thickness were controlled using a quartz crystal thickness monitor (Model FTM4, Edwards co, England). An X-ray diffractometer (Philips PW 3710BASED), using $\mathrm{CuK}_{\alpha}$ radiation operating at $40 \mathrm{kV}$ and $30 \mathrm{~mA}$, was used to investigate the structure.

Electrical resistivity measurements at various substrate temperatures were performed in the temperature range of $300 \mathrm{~K}$ to $550 \mathrm{~K}$ by the two probe technique using an electrometer (Keithly617). The ohmic contacts were made by evaporating high purity aluminum electrodes through a suitable mask onto the films. The ohmic nature of the contacts was confirmed by the linear J-V characteristics throughout the above mentioned temperature range. Thermoelectric power was measured using the differential technique [14].

\section{Results and Discussions}

\subsection{Structural Properties of $\mathrm{CdIn}_{2} \mathrm{Se}_{4}$ thin films}

Fig.(1) shows the XRD pattern of $\mathrm{CdIn}_{2} \mathrm{Se}_{4}$ thin films on glass substrates at different substrate temperatures. It can be seen that, over the studied range of substrate temperature, the films are polycrystalline and the most intense peak corresponds to plane (202). Other planes are also observed in all patterns. The intensity of diffraction peaks for the thin films has been found to increase and slightly shifts towards higher values of $2 \theta$ as the substrate temperature increased from 298 to 523K. Analysis of Fig.(1) indicates that $C d I n_{2} S_{4}$ thin films have cubic structure. For the cubic lattice parameters evaluation, we have used the quadratic relation:

$$
\mathrm{d}_{\mathrm{hkl}}=\mathrm{a} /\left[\mathrm{h}^{2}+\mathrm{k}^{2}+\mathrm{l}^{2}\right]^{1 / 2}
$$

where $(\mathrm{h}, \mathrm{k}, \mathrm{l})$ are the Miller indices of reflecting planes appearing in the diffraction spectrum and $\mathrm{d}_{\mathrm{h}, \mathrm{k}, \mathrm{l}}$ is the interplaner spacing. It was observed that both the calculated lattice parameter (a) and the unit cell volume $\left(\mathrm{V}=\mathrm{a}^{3}\right)$ were decreased as the substrate temperature was increased. The lattice constant 
values, $5.83 \AA$ at $298 \mathrm{~K}, 5.81 \AA$ at $460 \mathrm{~K}$ and $5.80 \AA$ at $523 \mathrm{~K}$ are in agreement with the standard values of $J C P D S$ data card $[11,15,17]$.

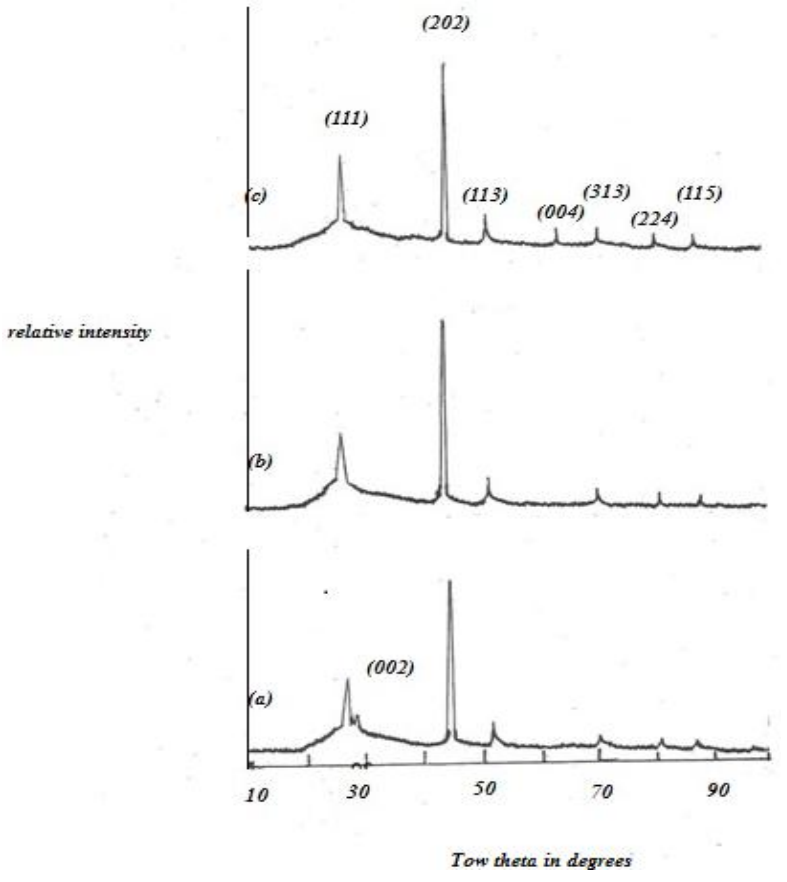

Fig.(1): XRD patterns of $C d \mathrm{In}_{2} \mathrm{Se}_{4}$ films with thickness $450 \mathrm{~nm}$ at: a) $298 \mathrm{~K}$, b) 460 and c) $523 \mathrm{~K}$.

The crystallite size of the samples is determined from x-ray data using Scherer's formula:

$$
D=k \lambda\left(\beta_{2 \theta} \cos \theta\right)^{-1}
$$

where $k=0.9$ is the shape factor, $\lambda$ is the wavelength of the $\mathrm{x}$-rays, $\beta_{2 \theta}$ is the full width half maximum (FWHM) and $\theta$ is the Bragg's angle. The x-ray analysis and calculated crystallite size are shown in Table (1). It is found that the crystallite size increases and full width half maximum (FWHM) decreases with substrate temperature. It is found that the crystallite size is ranged between 17.8 $\mathrm{nm}$ and $24.7 \mathrm{~nm}$ and increases with the substrate temperature. This is due to the sufficient supply of thermal energy for growth of the crystallites $[11,12,16]$. 
Table (1): The crystallite size(D) and the observed and standard d values for the $\mathrm{CdIn} \mathrm{Se}_{4}$ thin films deposited at various substrate temperature

\begin{tabular}{|c|c|c|c|c|c|c|c|}
\hline \multirow{3}{*}{$\begin{array}{c}\text { Standard } \\
\text { d-values } \\
\text { d }(\AA)\end{array}$} & \multirow{3}{*}{$\begin{array}{l}(h k l) \\
\text { planes }\end{array}$} & \multicolumn{6}{|c|}{ Substrate temperature (K) } \\
\hline & & \multicolumn{2}{|c|}{298} & \multicolumn{2}{|c|}{460} & \multicolumn{2}{|c|}{523} \\
\hline & & $\mathrm{d}(\AA)$ & $\mathrm{D}(\mathrm{nm})$ & $\mathrm{d}(\AA)$ & $\mathrm{D}(\mathrm{nm})$ & $\mathrm{d}(\AA)$ & $\mathrm{D}(\mathrm{nm})$ \\
\hline 3.370 & $\left(\begin{array}{lll}1 & 1 & 1\end{array}\right)$ & 3.371 & \multirow[t]{5}{*}{17.8} & 3.362 & \multirow[t]{5}{*}{21.3} & 3.361 & \multirow[t]{5}{*}{24.7} \\
\hline 2.060 & $\left(\begin{array}{lll}2 & 0 & 2\end{array}\right)$ & 2.061 & & 2.059 & & 2.058 & \\
\hline 1.750 & $\left(\begin{array}{lll}1 & 1 & 3\end{array}\right)$ & 1.779 & & 1.775 & & 1.770 & \\
\hline 1.330 & $\left(\begin{array}{lll}3 & 1 & 3\end{array}\right)$ & 1.341 & & 1.341 & & 1.340 & \\
\hline 1.190 & $(224)$ & 1.182 & & 1.181 & & 1.180 & \\
\hline
\end{tabular}

\subsection{Electrical resistivity of $\mathrm{CdIn}_{2} \mathrm{Se}_{4}$ thin films}

The dark electrical resistivity, $\rho$, of $C d I n_{2} S_{4}$ films of different thicknesses grown at $298 \mathrm{~K}$ was measured as a function of the sample temperature. The temperature dependence of $\rho$, in the range of 300-450K, is shown in Fig.(2) for different film thickness. It indicates a decrease of $\rho$ against $T$. A linear relationship for each sample with distinct slope is obtained. The corresponding thermal activation energies, $\Delta E$, were estimated utilizing the following equation:

$$
\rho=\rho_{o} \exp (\Delta E / k T)
$$

where, $\rho_{o}$ is the resistivity of $C d \operatorname{In}_{2} \mathrm{Se}_{4}$ film of thick thickness, and the other symbols have their usual meanings.

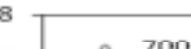

$1000 / \mathrm{T}(\mathrm{K})$

Fig.(2): $\log \rho$ versus 1000/T for $C d I n_{2} \mathrm{Se}_{4}$ thin films for different film thickness, deposited at $298 \mathrm{~K}$.

The calculated $\Delta E$ for $C d I_{2} S_{4}$ of different thicknesses are given in Table(2). The low value of $\Delta E$ indicates that $C d \operatorname{In}_{2} \mathrm{Se}_{4}$ thin film behaves as an extrinsic semiconductor. Such behaviour can be attributed to lattice defects such as vacancies, interstitials and dislocations which might be developed throughout the first stages of the film growth. From Fig.(2), the dark electrical resistivity of 
$\mathrm{CdIn}_{2} \mathrm{Se}_{4}$ thin films, at given constant temperature, tends to decrease with increasing film thickness. The reduction of the dark electrical resistivity with increasing the film thickness may also be attributed to the increase in the size of the individual crystallites as obtained from the structural analysis.

Table(2): The thermal activation energy, $\Delta E(\mathrm{eV})$ at various film thickness, deposited at room temperature (298K).

\begin{tabular}{|l|l|l|l|l|l|}
\hline$d(\mathrm{~nm})$ & 160 & 300 & 400 & 500 & 700 \\
\hline$\Delta E(\mathrm{eV})$ & 0.32 & 0.27 & 0.22 & 0.16 & 0.11 \\
\hline
\end{tabular}

\subsection{Effect of substrate temperature on electrical resistivity of $\mathrm{CdIn}_{2} \mathrm{Se}_{4}$ thin} films

Fig.(3) illustrates the relation between the dark electrical resistivity and reciprocal of temperature for $\mathrm{CdIn}_{2} \mathrm{Se}_{4}$ thin films of various substrate temperatures for a constant film thickness $(450 \mathrm{~nm})$.

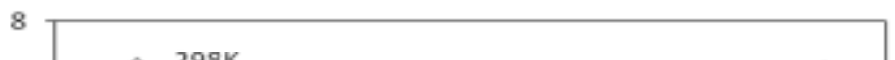

$1000 / \mathrm{T}(\mathrm{K})$

Fig.(3): $\log \rho$ versus $1000 / \mathrm{T}$ for $C d \operatorname{In}_{2} \mathrm{Se}_{4}$ thin films deposited at various substrate temperatures.

It reveals that the resistivity obeys the relation:

$$
\rho=\rho_{o} \exp \left(E_{a} / k_{B} T\right)
$$

where $E_{a}$ is the activation energy at different substrate temperature and $k_{B}$ is the Boltzmann constant. It is clear from Fig.(3) that the resistivity decreases with the increase of temperature [12,18].The estimated values of activation energies for different substrate temperatures and are tabulated in Table(3). For the film deposited at room temperature (298K) shows room temperature resistivity in order of $10^{7} \Omega \mathrm{cm}$, while it decreases to $10^{2} \Omega \mathrm{cm}$ for that deposited at $523 \mathrm{~K}$.A 
corresponding decrease in the activation energy from $0.32 \mathrm{eV}$ to $0.22 \mathrm{eV}$ was observed. Such changes in both activation energy and resistivity as a result of increase substrate temperature can be ascribed to the increase in crystallite size.

Table(3):The thermal activation energy, $\Delta E(\mathrm{eV})$ at various substrate temperatures

\begin{tabular}{|l|l|l|l|l|l|c|}
\hline$T_{s}(K)$ & 298 & 330 & 380 & 395 & 460 & 523 \\
\hline$\Delta E(\mathrm{eV})$ & 0.32 & 0.217 & 0.230 & 0.244 & 0.257 & 0.271 \\
\hline
\end{tabular}

3.5. Effect of substrate temperature on thermoelectric power of $\mathrm{CdIn}_{2} \mathrm{Se}_{4}$ films

Fig.(4) represents the variation of thermoelectric power, $\mathrm{S}$ for $\mathrm{CdIn}_{2} \mathrm{Se}_{4}$ films deposited at various substrate temperatures, against temperature. In general, all samples have negative Seebeck coefficient indicating that $\mathrm{CdIn}_{2} \mathrm{Se}_{4}$ films behave as n-type semiconductors. High thermoelectric power is observed for the film grown at $460 \mathrm{~K}$. This is due to high crystallinity which confirms the optimized substrate temperature of $460 \mathrm{~K}[12,18]$.

0.07

$T(K)$

Fig.(4): Variation of thermoelectric power, $S$ with temperature, $T$ for $C d I_{2} \mathrm{Se}_{4}$ thin films deposited at various substrate temperatures.

The thermoelectric power was described by the following equation [19]:

$$
S=\left(k_{B} / e\right)\left[A+\ln \left(N_{n} / N\right)\right]
$$

where $N_{n}$ is given by [19 ]:

$$
N_{n}=2 M^{3 / 2}=2.5 \times 10^{19}(T / 300)^{3 / 2}\left(m^{*} / m_{o}\right)^{3 / 2}
$$

where $\mathrm{M}=2 \pi \mathrm{m}^{*} k_{B} T / h^{2}, \mathrm{~m}^{*}$ is the effective mass of the electron $\left(\mathrm{m}^{*}=0.15 \mathrm{~m}_{\mathrm{o}}\right.$ [19]) and the symbols have their usual meanings. The measured thermoelectric power of $C d I_{2} S_{4}$ is used to estimate the concentration of the free charge carrier, $\mathrm{N}$, for $\mathrm{CdIn}_{2} \mathrm{Se}_{4}$ thin films as following: 


$$
\mathrm{N}=2.5 \times 10^{19}(\mathrm{~T} / 300)^{3 / 2}\left(\mathrm{~m} * / \mathrm{m}_{o}\right)^{3 / 2} \exp \left(2-1.16 \times 10^{4} \mathrm{~S}\right)
$$

The free charge carrier concentration for $C d I_{2} \mathrm{Se}_{4}$ thin films calculated from thermoelectric power measurements are given in Table(4). It is clear that the carrier concentration were decreased as results of substrate temperature, since the values of thermoelectric power were increased as results of substrate temperature.

Table(4): The free charge carrier concentration, $N\left(10^{18} \mathrm{~cm}^{-3}\right)$ of $\mathrm{CdIn}_{2} \mathrm{Se}_{4}$ thin films calculated from thermoelectric power measurements with different substrate temperature.

\begin{tabular}{|c|c|c|c|c|c|}
\hline \multirow{2}{*}{$\mathrm{T}(\mathrm{K})$} & \multicolumn{5}{|c|}{ Substrate temperatures, $\mathrm{C}$} \\
\cline { 2 - 6 } & 298 & 330 & 380 & 395 & 460 \\
\hline 298 & 7.014 & 6.542 & 6.102 & 5.659 & 5.2482 \\
\hline 318 & 7.554 & 7.046 & 6.573 & 6.095 & 5.653 \\
\hline 338 & 8.259 & 7.704 & 7.186 & 6.664 & 6.180 \\
\hline 358 & 8.971 & 8.368 & 7.806 & 7.239 & 6.713 \\
\hline 378 & 9.711 & 9.058 & 8.449 & 7.835 & 7.266 \\
\hline 398 & 10.46 & 9.752 & 9.097 & 8.436 & 7.823 \\
\hline 418 & 11.23 & 10.47 & 9.768 & 9.059 & 8.401 \\
\hline 438 & 12.01 & 11.21 & 10.45 & 9.694 & 8.990 \\
\hline 458 & 12.83 & 11.97 & 11.16 & 10.35 & 9.602 \\
\hline 478 & 13.67 & 12.75 & 11.89 & 11.03 & 10.23 \\
\hline 498 & 14.53 & 13.55 & 12.64 & 11.72 & 10.872 \\
\hline
\end{tabular}

\subsection{Effect of substrate temperature on grain boundary potential barrier}

Using the concentration of free charge carrier obtained from thermoelectric power measurements with the resistively data for the same samples, the mobility, $\mu(=1 / e \rho N)$, at any given temperature for different substrate temperature was calculated. Fig.(5) shows the variation of $\log (\mu)$ versus $\frac{1000}{T}$. It is clearly noticed that the mobility, $\mu$, for each film obeys a relation described by [20]:

$$
\mu=\mu_{o} \exp \left(-q \phi_{b} / k_{B} T\right)
$$


where $\phi_{b}$ is the barrier potential of the grain boundary and $\mu_{\mathrm{o}}$ is the grain boundary limited mobility and $q$ is the electronic charge. Regarding the slope of each curve the mobility activation energy, $q_{\phi_{b}}$, for each substrate temperature can be evaluated. The obtained mobility activation energy $\left(q \phi_{b}\right)$ is given in

$1.00 \mathrm{E}+00$

1 กnE.n1 $\longrightarrow 298 \mathrm{~K}$

$1000 / \mathrm{T}(\mathrm{K})$

Fig.(5): $\log (\mu)$ versus $\left(\frac{1000}{T}\right)$ for $C d \operatorname{In}_{2} S e_{4}$ thin films at various substrate temperatures.

Table (5) in comparison with the thermal activation energy $(\Delta E)$ for substrate temperature. It can be observed from the table that the substrate temperature governs the potential barriers at grain boundaries. The higher the substrate temperature the lower the potential barrier at grain boundaries and hence the lower is the mobility activation energy. In addition the values of mobility activation energy $\left(q \phi_{b}\right)$ are likely smaller than the thermal activation $\operatorname{energy}(\Delta E)$.

Table(5): The mobility activation energy in comparison with thermal activation energy at various substrate temperature.

\begin{tabular}{|c|c|c|}
\hline$T_{S}(\mathrm{~K})$ & $\Delta \mathrm{E}(\mathrm{eV})$ & $q \phi_{b}(\mathrm{eV})$ \\
\hline 298 & 0.32 & 0.275 \\
\hline 330 & 0.217 & 0.182 \\
\hline 380 & 0.230 & 0.182 \\
\hline 395 & 0.244 & 0.214 \\
\hline 460 & 0.257 & 0.215 \\
\hline
\end{tabular}




\section{Conclusions}

Analysis of the X-ray diffraction data showed that $\mathrm{CdIn}_{2} \mathrm{Se}_{4}$ films are highly oriented along (202) planes. The deposited films are of polycrystalline nature with cubic structure. Nano crystallite size of $17.8-24.7 \mathrm{~nm}$ has been recognized. The increase in crystallite size as results of substrate temperature indicates the structure improvement of $\mathrm{CdIn}_{2} \mathrm{Se}_{4}$. Room temperature resistivity for the film deposited at $298 \mathrm{~K}$ is found to be of order of $10^{7} \Omega \mathrm{cm}$, while it decreases to $10^{2} \Omega \mathrm{cm}$ for the sample deposited at $523 \mathrm{~K}$. Correspondingly, the activation energy decreased from $0.32 \mathrm{eV}$ to $0.22 \mathrm{eV}$. The reduction of the dark electrical resistivity as function of film thickness may be due to the increase in crystallite size. Also, the electrical resistivity of $\mathrm{CdIn}_{2} \mathrm{Se}_{4}$ decreases with increasing the film thickness can be attributed to lattice defects such as vacancies, interstitials and dislocations which might be augmented throughout the first stages of the film growth. These defects add an extra percentage of resistivity. These defects diffuse and accordingly the corresponding resistivity decreases as the film thickness increases. Thermoelectric power measurements showed that $\mathrm{CdIn}_{2} \mathrm{Se}_{4}$ thin films are n-type semiconductor with carriers concentration in the order of $7.01 \times 10^{18} \mathrm{~cm}^{-3}$, at $298 \mathrm{~K}$. The behavior of resistivity with temperature and the low value of $\Delta E$ indicate that $C d I_{2} S_{4}$ thin film behaves as an extrinsic semiconductor.

\section{References}

1. R. Tenne, Y. Mirovsky, G. Sawatzky and W. Giriat, J. Electrochem. Soc., 132, 1829 (1985).

2. S. Choe, B. Park, K. Yu, S. Oh, H. Park and W. Kim, J. Phys. Chem. Solids, 56, 89 (1995).

3. R. YehudithMirovsky, Y.Greenstein, D. Cahen, J. Electrochem. Soc., 129, 1506 (1982).

4. T. Mahalingam, A. Kathalingam, S.Velumani, S. Lee, K.S. Lew, Y.D. Kim, Semicond. Sci., Technol. 20, 749 (2005).

5. E.A. Dalchiele, S. Cattarin, M.M. Musiani, J. Appl. Electrochem, 28, 1005 (1998).

6. J. Ahn, G. Rajaram S. Mane, V.V. Todkar, A.V. Shaikh, H. Chung, M.Y. Yoon, S.H. Han, Appl. Surf. Sci., 253, 8588 (2007).

7. S. Thanikaikarasan, T. Mahalingam, A. Kathalingam, Y.D. Kim, T. Kim, Vacuum 83, 1066 (2009).

8. S. Thanikaikarasan, T. Mahalingam, M. Raja, T.Kim, Y.D. Kim, J. Mater. Sci: Mater., El. 20, 727 (2009). 
9. T. Mahalingam, S. Thanikaikarasan, R. Chandramohan, M. Raja, C. Sanjeeviraja, J. H.Kim, Y.D.Kim, Mater. Chem. Phys. 106, 369 (2007).

10. T.Mahalingam, S.Thanikaikarasan, R.Chandramohan, K.Chung, J.P.Chu, S.Velumani, J.K.Rhee, Materials Science and Engineering B 174, 236 (2010).

11. V.M. Nikale, N.S. Gaikwad, K.Y. Rajpure, and C.H. Bhosale, Mater. Sci. Eng., B 78, 363 (2002).

12. V. M.Nikale, U.B.Suryavanshi and C.H.Bhosale, Mater. Sci. Eng. B, 134, 94 (2006).

13. S. Tolansky "Multiple-bem" Interferometry of Surface and Films, London, Oxford, 147 (1988).

14. A.A. El Shazly, D. Abd Elhady, H.S. Metwally and M.A.M. Seyam, J. Pys. Condence Matter, 10, 5943 (1998).

15. JCPDS diffraction data file no. 17, 356 (1996).

16. V.M. Nikale, C.H. Bhosale, Sol. Energy Mater. Sol. Cells, 82, 10 (2004).

17. JCPDS Card No. 8-459 (1992).

18. S. Glenis, A.J. Frank, Synth, Met., 28, C681 (1989).

19. S. Koval, E.K. Arushanov, S.I. Radautsan, Status Solidi, (a) 9 k73, 148 (1972).

20. R.L. Petriz, Phys. Rev., 104, 1506 (1956). 